\title{
CONSECUENCIAS BIBLIÓFILAS DE LAS EMBAJADAS ENTRE ESPAÑA E IRÁN DEL SIGLO XVII
}

\author{
Fernando Escribano Martín \\ (Universidad Autónoma de Madrid)
}

\begin{abstract}
RESUMEN
A principios del siglo XVII, se publicaron un inusual número de libros que tenian como objeto el viaje a Oriente y el análisis politico de aquel y otros territorios. Estas publicaciones se dieron en el ámbito de la Monarquía Hispánica y son buena muestra del interés por aquellas tierras y de la importancia política que todavía mantenía una estructura en decadencia.

Algunos de estos textos son consecuencia directa del importante trasiego de embajadas que se dieron entre España e Irán en pocos años, pero otros responden a una visión más amplia y a unos intereses también más globales. El éxito de estos textos fue desigual, pero no es exagerado hablar de la importancia significativa de varios de ellos. Algunos de los estudios o narraciones se convirtieron en material bibliófilo por la relevancia del libro pero también por su casi total desconocimiento, de modo que podemos hablar de joyas ocultas en bibliotecas privadas que hacian las delicias de unos pocos hasta que fueron publicadas, algunas siglos después de su escritura.

La mera enumeración de estos libros, concentrados en muy pocos años, sorprende, y sus textos forman un corpus de conocimiento sobre Irán o sobre el mundo que se estaba explorando en aquellos años (visión europea) que fue relevante durante un largo periodo de tiempo.
\end{abstract}

\section{PALABRAS CLAVE}

Irán, Monarquía Hispánica, viaje, embajadas, Comentarios, Relaciones.

\section{BIBLIOPHILE CONSEQUENCES OF THE EMBASSIES BETWEEN SPAIN AND IRAN IN THE 17TH CENTURY}

\begin{abstract}
At the beginning of the seventeenth century, an unusual number of books were published that had as their object the trip to the East and the political analysis of that and other territories. These publications were given in the context of the Hispanic Monarchy and are good evidence of the interest in those lands and the political importance that still maintained a structure in decline.

Some of these texts are a direct consequence of the important movement of embassies that occurred between Spain and Iran in a few years, but others respond to a broader vision and to more global interests. The success of these texts was uneven, but it is not an exaggeration to speak of the significant importance of several of them. Some of the studies or narrations became bibliophile material because of the relevance of the book but also because of its almost total ignorance, so we can talk about hidden gems in private libraries that delighted a few until they were published, some of them centuries later of his writing.

The mere enumeration of these books, concentrated in a few years, surprises, and their texts form a corpus of knowledge about Iran or about the world that was being explored in those years (European vision) that was relevant for a long period of time.
\end{abstract}

\section{KEY WORDS}

Iran, Spanish Monarchy, trip, embassies, Comments, Relations. 
La historia del sorprendente intercambio de embajadas que se dio entre el Irán safávida y algunas cortes europeas en el siglo XVII ha sido tratado en otros foros y estudios ${ }^{1}$, y aquí, de hecho, haremos un leve resumen al respecto para hablar de sus consecuencias bibliográficas. Independientemente de los contactos establecidos con otras cortes europeas, una parte importante de las embajadas señaladas se dieron entre las cortes hispánica e iraní, algunas de las cuales fueron narradas en unos textos ${ }^{2}$ absolutamente únicos escritos por sus protagonistas. Algunos de estos escritos fueron rápidamente traducidos a las lenguas europeas, y se mantuvieron como referencia del conocimiento del mundo iraní durante mucho tiempo. Estos textos a los que haremos referencia en esta comunicación no fueron solo narraciones del trayecto recorrido o de estudios realizados sobre distintos asuntos a colación, algunos de los cuales son únicos y ya hubiesen justificado la importancia que les estamos dando, sino que también, como resultado de estos contactos, tenemos tres tratados de política internacional ${ }^{3}$ que aportan una visión geoestratégica universal o local muy relevante, y que estaban dirigidos a la Monarquía Hispánica.

De forma paralela, y aunque no son resultado de estos contactos, pero sí unidos en cuanto a la visión y al viaje por el mundo en el siglo XVII, haremos referencia y relación de varios viajes que, saliendo desde España o Portugal, llegaron a tierras iranias y más allá, y que conforman también esa visión holística de los países relacionados entre sí, formando ya un sistema mundo, que son viajados y luego narrados, y que dan como resultado varios libros publicados también a principios del siglo XVII.

Es obvio que a finales del siglo XVI y sobre todo a principios del XVII, se dio un afán por conocer aquel Oriente en parte controlado por Portugal (entre 1580 y 1640 gobernado por la Monarquía hispánica), donde otras potencias europeas querían tomar relevancia. Esta situación coincide y en parte es propiciado por un reinado iraní del shah Abbas I que no quería ser mera comparsa de nadie y que de hecho pretendía revitalizar su poder regional. La proliferación de contactos que se dio en esta circunstancia tuvieron su plasmación en toda una serie de tratados políticos, comentarios de viaje y de historia y publicaciones de distinto orden, que sentaron las bases del conocimiento europeo de aquellas tierras. Este afán de conocimiento del Oriente Próximo forma parte del aluvión de exploraciones y viajes que en un mundo en descubrimiento se estaban dando en su conjunto, no es algo exclusivo, pero sí que es sorprendente la cantidad de publicaciones que se dieron en pocos años y que tenían como objeto de narración o estudio Irán.

\footnotetext{
${ }^{1}$ El que libro que mejor documenta estas embajadas entre España e Irán, muy bien documentado y apegado a las fuentes, es el de Luis Gi (2006 y 2009): El Imperio luso-español y la Persia safávida. En una perspectiva más amplia, temporal y espacial, desde parte española, es imprescindible consultar el número de Arbor coordinado por el profesor Córdoba: Españoles en Oriente Próximo (1166-1926). Aventureros y peregrinos, militares, cientificos y diplomáticos olvidados en el redescubrimiento de un mundo (2005), y el catálogo de la exposición celebrada en el Museo Arqueológico Nacional en 2006, comisariada por Joaquín Mª Córdoba Zoilo y M. Carmen Pérez Díe: La aventura española en Oriente (1166-2006). Viajeros, museos y estudiosos en la historia del redescubrimiento del Oriente Próximo Antiguo.

${ }^{2}$ En este grupo de textos hay que referirse a los Comentarios de don García de Silva y Figueroa, o a las Relaciones de don Juan de Persia.

${ }^{3}$ El caso más claro es el de Anthony Sherley, El Peso de todo el mundo, un estudio geoestratégico mundial, pero del mismo modo, a un nivel más localizado, las Relaciones de Pedro Teixeira del origen, descendencia y sucesión de los reyes de Persia, y de Hormuz, basándose en la crónica de un autor iraní, o una parte de las Relaciones de don Juan de Persia, que hacen referencia a la historia de Persia y sus contactos con la española, deben ser incluidas entre estos estudios geopolíticos.
} 


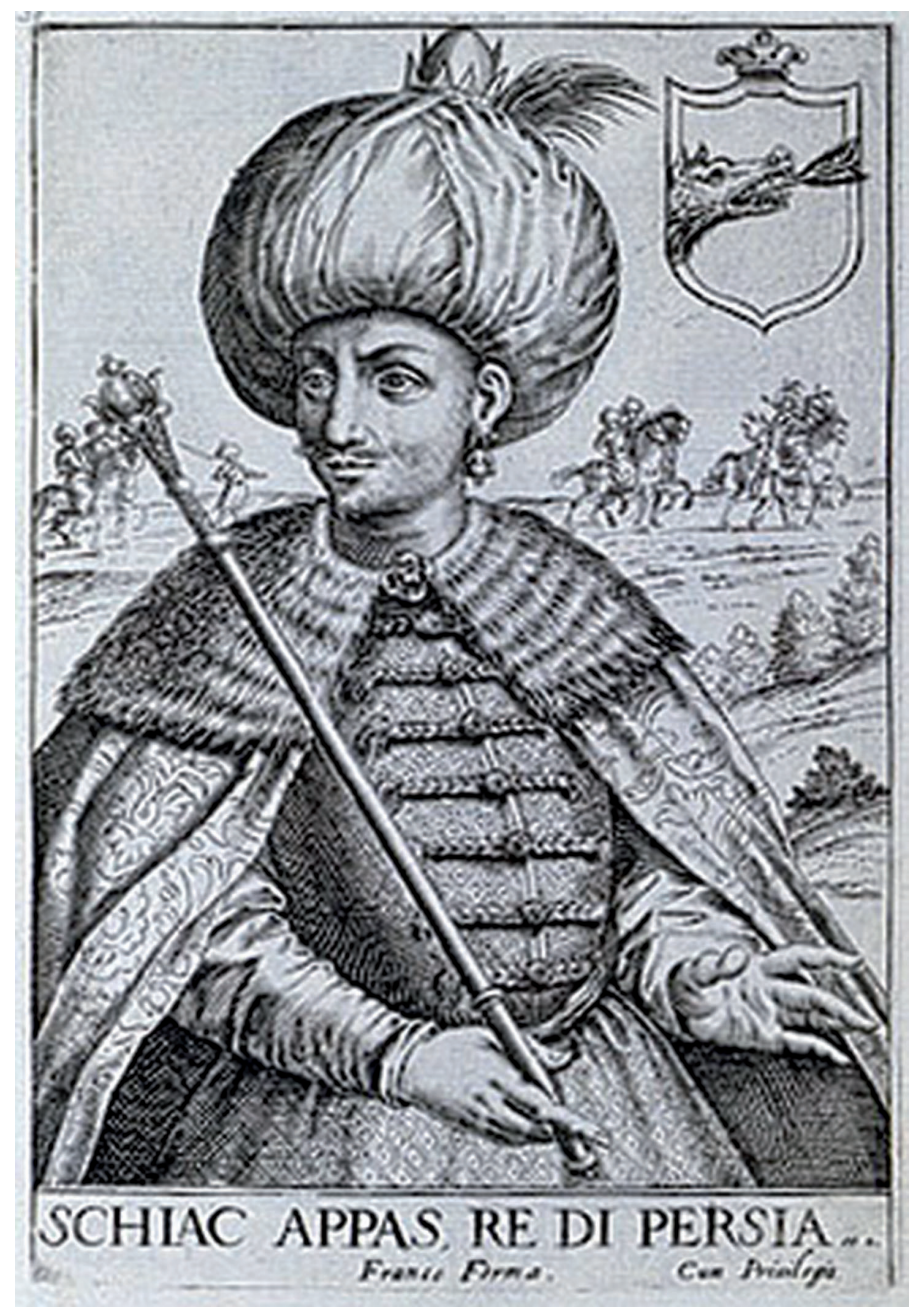

Fig. 1.- El shah Abbas I.

\section{Las embajadas entre España e Irán}

La pretensión de atacar al turco desde dos frentes no es nueva, y ya en el siglo XV se envió una embajada a Tamorlán con esta intención, ordenada por Enrique III de Castilla, y bajo el mando de Ruy González de Clavijo ${ }^{4}$, que da como resultado bibliográfico el considerado primer libro de viajes europeo. También de aquel tiempo queda constancia de viajes que describen lejanas tierras aunque no hubiese misión aparente que lo justificase y, hacia mediados de siglo, se publican las Andaças e viajes de Pero Tafur ${ }^{5}$, que narra el periplo realizado entre 1436 y 1439 por el Mediterráneo y Oriente Próximo.

Las embajadas que entre Irán y las cortes europeas se dieron en el siglo XVII parten del acercamiento diplomático a Persia de Felipe $\mathrm{II}^{6}$, que a su vez parte de la embajada prevista al shah Tahmasp de Persia por el emperador Maximiliano $\mathrm{II}^{7}$ en

\footnotetext{
${ }^{4}$ Ver por ejemplo la Embajada a Tamerlan, de Ruy González de Clavijo, editada por Miraguano Ediciones en 1999.

${ }^{5}$ En la Biblioteca de Viajeros Hispánicos, Miraguano Ediciones y Ediciones Polifemo, editaron en 1995 Andanzas y viajes de un hidalgo español, de Pero Tafur.

${ }^{6}$ Este es el título del capítulo segundo del fundamental estudio llevado al respecto por Luis Gil sobre las relaciones entre la Persia safávida y la Monarquía hispánica.

${ }^{7}$ Gil, 2006, 57 y ss.
} 
1566. Después de la batalla de Lepanto (7 de octubre de 1571), a iniciativa del rey de Portugal don Sebastián, se escriben varias cartas al shah con la pretensión de organizar el ataque a la Sublime Puerta desde dos frentes. Posteriormente, Venecia firmaría la paz con Turquía en 1574, modificando la red de alianzas preexistente, y es cuando don Juan de Austria también interviene en el asunto con Persia ${ }^{8}$. La idea del papado y de la Casa de Austria de formar una alianza con Persia frente al turco será desde entonces recurrente'.

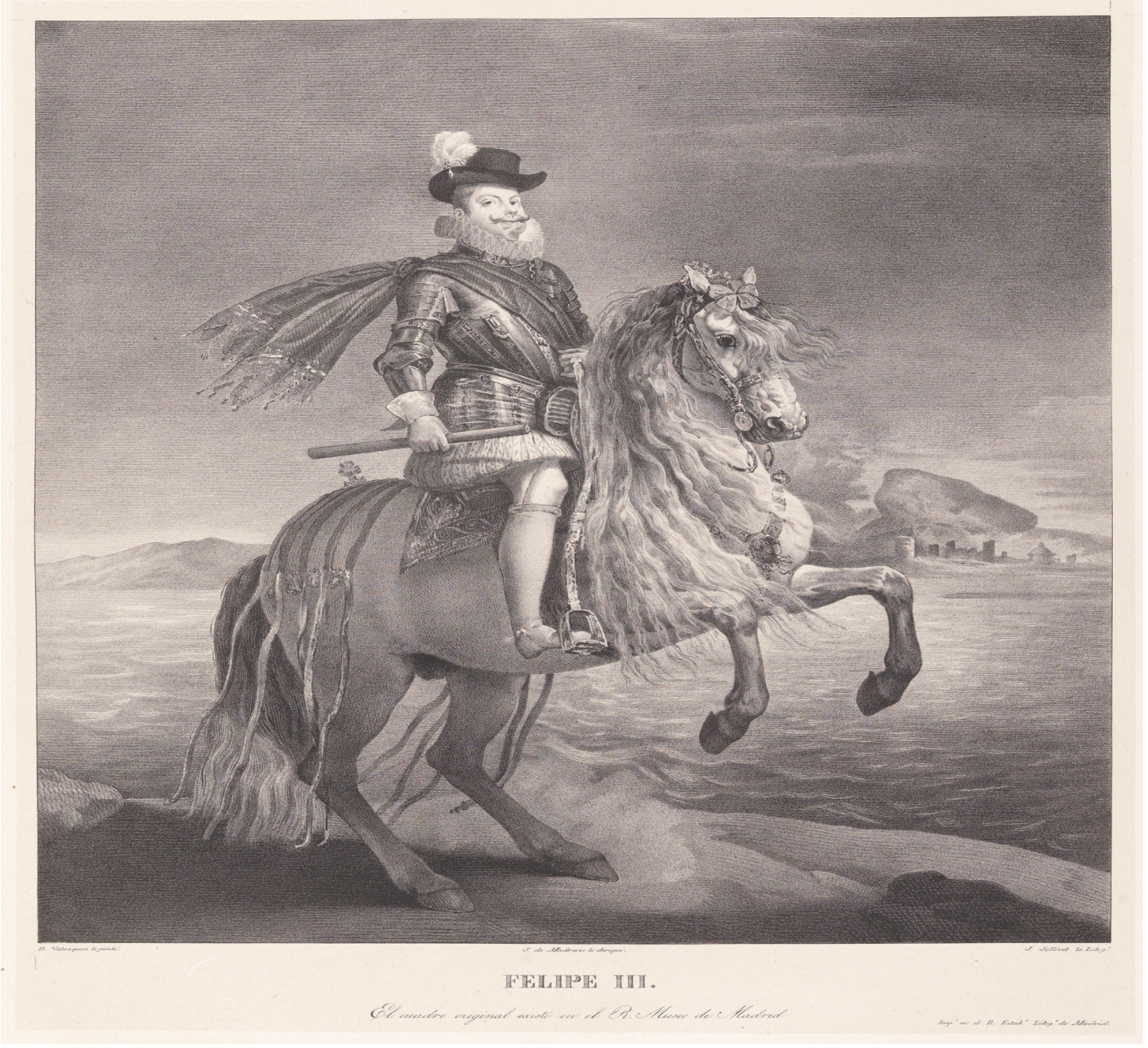

Fig. 2.- Felipe III, a caballo. 1829 - 1832. Aguatinta litográfica, Litografía a lápiz sobre papel avitelado, $630 \times 485$ mm. Litografía de Pierre-Jules Jollivet (1794-1871). Museo del Prado, Madrid. La mayor parte de los viajes y embajadas de los que hablamos en esta comunicación se dieron bajo su reinado (r. 1598-1621).

Es el shah Abbas I (17 de enero 1571 - 19 de enero de 1629, r. 1588-1629) quien retoma con fuerza aquellos primeros contactos. 1598 sería la fecha clave por la aparición de Anthony Sherley en Persia. Junto al agustino Nicolás de Melo se dijeron delegados del papa

\footnotetext{
${ }^{8}$ Gil, 2006, 69.

${ }^{9}$ Gil, 2006, 71 .
} 
y del rey de España para buscar una alianza frente al turco ${ }^{10} \mathrm{y}$ así se lo plantearon al shah. En 1613 se publicará en Londres su Travels into Persia, donde cuenta su versión de lo sucedido en la gestación de esa misión.

A partir de la influencia de estos personajes, y sin duda por todos los contactos previos ya mencionados, Abbas I decide enviar una embajada a los príncipes cristianos al mando del noble persa Husein/Uzén Ali Beg y de Anthony Sherley. La diplomacia vaticana, o al menos las órdenes implicadas en la zona, actuaban por sus propios cauces, y solo a veces coincidía con los intereses de los monarcas europeos. No vamos a narrar las increíbles peripecias de esta embajada" ${ }^{11}$, ni vamos a pretender analizar al personaje Anthony Sherley ${ }^{12}$, pero sí nos interesa destacar que en esta embajada, formada por cuatro caballeros persas y quince criados, dos frailes, don Anthony, cinco intérpretes y quince ingleses, marchaba Uruch Beg, el futuro Juan de Persia, que se convirtió y se quedó en España junto a otros compatriotas, y que sería el autor de unos Comentarios que citaremos más adelante.

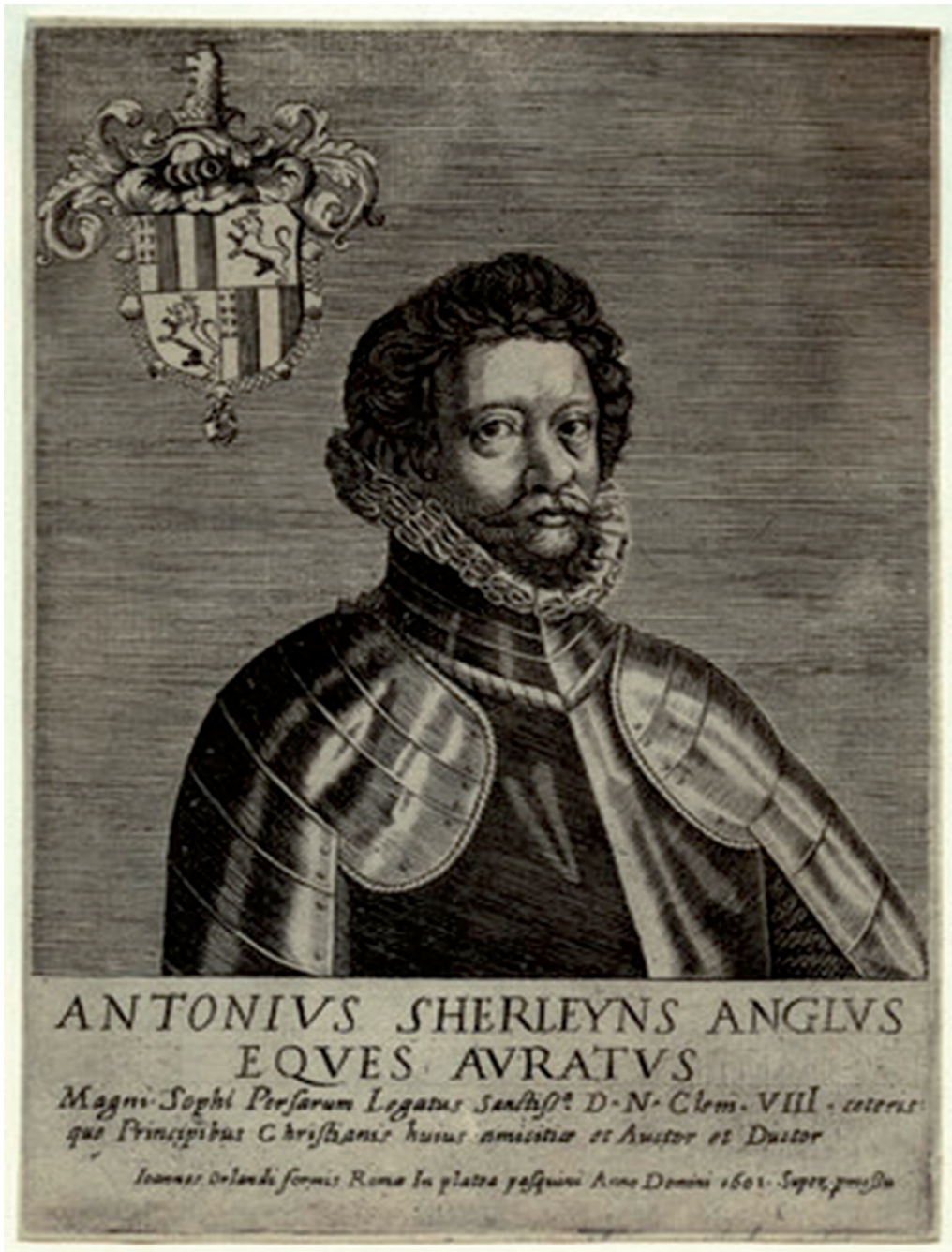

Fig. 3.- Sir Anthony Sherley at the Court of Shah Abbas the Great, 1599. Illustration for Story of the British Nation (Hutchinson, c 1920).

\footnotetext{
${ }^{10}$ Gil, 2006, 80.

${ }^{11}$ Ver al respecto el trabajo de Gil, 2006 y 2009.

${ }^{12}$ Sobre el personaje, ver por ejemplo la introducción a la edición de su Peso político de todo el mundo hecha por Viñas y Mey (1961), o los textos introductorios de la edición de 2010 del mismo escrito, junto a otro tratado también suyo: Discurso sobre el aumento de esta monarquía.
} 
Esta embajada bicéfala se terminaría dividiendo en Roma en $1601^{13}$, y ambos embajadores, por separado, terminarían marchando a España. La vida de Anthony Sherley es cuanto menos azarosa. Católico inglés, estudió en Oxford y estuvo involucrado en distintas misiones militares vinculadas al conde de Essex. No queda claro con qué motivo, el 24 o 25 de mayo de 1598 embarca rumbo a Alepo ${ }^{14}$, y comienza así su aventura persa.

De Roma, tras su ruptura con Uzén Alí Bey, desaparece, y termina apareciendo en Venecia, vinculado al servicio español a partir de 1602. Encarcelado, es liberado el 8 de mayo de $1603{ }^{15}$ y desde Italia mantiene una labor intermediaria entre la corte española y la persa, sobre otros asuntos internacionales, comerciales, y sobre todo cuidando de los suyos propios. Regresó a España a principios de enero de $1611^{16}$ y es desde entonces cuando más proyectos presenta a la Administración española. Estos memorandos y proyectos serán acogidos por parte de la corte con una mezcla de admiración, miedo, precaución, curiosidad y también al final hartazgo, con una sensación generalizada de mejor tener al personaje controlado que no como enemigo, hasta que el inglés desaparece de la escena, no sabemos cómo ni cuándo.

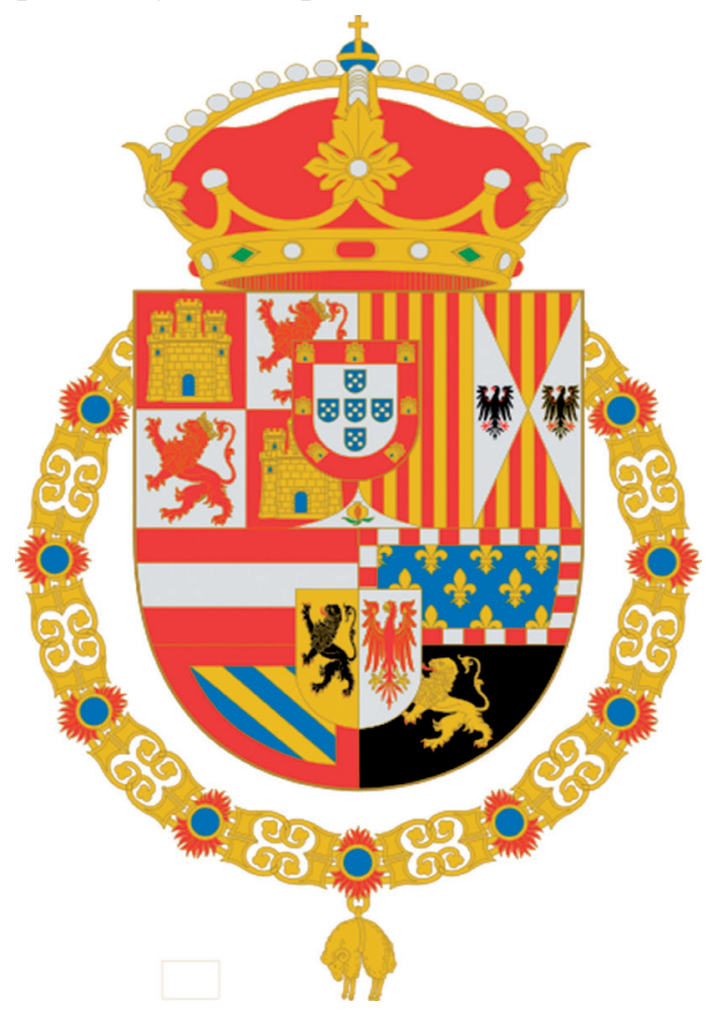

Fig. 4.- Escudo de Armas de Felipe II a Carlos II. Con la proclamación de Felipe II como rey de Portugal, se incorpora su escudo hasta el reconocimiento de su independencia en 1668.

Se fueron sucediendo distintas embajadas entre Irán y las cortes europeas, toda vez que la de Anthony Sherley no da respuesta. Es su hermano Robert, que había quedado como rehén en la corte safávida, a tiempos formando al ejército persa, quien acabó siendo también embajador del shah persa, marchando a la búsqueda de su hermano, pero sobre todo para acuciar en la intención última, que era afianzar y hacer efectiva la alianza contra la Sublime Puerta.

\footnotetext{
${ }^{13}$ Gil, 2006, 123.

${ }^{14}$ Gil, 2006, 152.

${ }^{15}$ Gil,2006, 169.

${ }^{16}$ Gil, 2006, 240.
} 
Tras la embajada de Danguis Beg y el obispo de Cirene, a lo largo de 1612, en la corte española se entendía urgente la necesidad de mandar una respuesta al shah ${ }^{17}$. El embajador elegido será don García de Silva y Figueroa, de Zafra ${ }^{18}$, nacido el 11 de abril de 1548. La preparación, negociación y organización de la embajada fue larga y tediosa, como solo sabe comprender quien lidia con la Administración española, y la elección de los presentes que se enviarían al shah no fue menos costoso de resolver.

El 8 de abril de 1614, desde Lisboa, la flota se hizo a la mar, tarde para coger los mejores vientos alisios. El 6 de noviembre de 1614 llegaron a Goa. La descripción y el mapa que aparecen en los Comentarios de don García sobre la ciudad clave de Portugal en la zona, son dignos de referencia y elogio. El embajador enviará informes sobre las defensas y la administración de los lugares más importantes por los que va pasando, además de referir el mal trato del que es objeto por parte de las autoridades portuguesas, Leyendo la narración de don García se van entendiendo las causas del mal gobierno luso de esta porción de su imperio: una mezcla de corrupción, mal gobierno y hartazgo por parte de todos los implicados, tanto los gobernantes y sus estructuras como los gobernados, situación que aprovechan las potencias locales y los europeos que se quieren posicionar en estas tierras.

Parte para Ormuz el 21 de marzo de 1617. En el intervalo, Robert Sherley y fray Redempto de la Cruz, enviados por el shah a la corte española, son recibido en Goa con boato $^{19}$, pese a los informes en contra y precauciones enviados por nuestro embajador. Está claro el trato que le deparan las autoridades locales a uno y a otros, sin respetar rangos ni los supuestos intereses que debieran defender. Es muy interesante también observar el continuo flujo de embajadas que se cruzan las cortes iraní e hispánica. Don García llegó a Ormuz el 29 de mayo de 1617.

En los primeros días de abril de 1618 visitó Chilminara, Persépolis, y si bien no es el primero en descubrirlo ${ }^{20}$, ni quizá el primero en identificar el cuneiforme como lengua escrita, sí es el primero en describirla, estudiarla y traer imágenes a Europa, tanto del lugar como dela escritura, realizando un trabajo soberbio en erudición y precisión. Tenía una intención clara de hacer comprender lo que él había visto. La importancia de su trabajo al respecto todavía no está reconocida en su justa medida por los orientalistas.

En Qazvín, en el verano de 1618, se reúne con el shah y con los líderes de su administración, también con otros embajadores como el turco, tártaro, cosaco o el italiano Pietro della valle ${ }^{21}$.

Solo el 25 de agosto de 1619 pudo salir de Ispahán camino de vuelta a casa. Llegó a Shiraz el 7 de septiembre y el 18 a Ormuz. A Goa llegó el 20 de abril de 1620. Ya en ruta a España, de Mozambique tuvo que regresar a Goa, y solo se pudo volver a embarcar definitivamente, por retrasos de distinta índole, el 28 de enero de 1624. No llegó a España,

\footnotetext{
${ }^{17}$ Gil, 2009, 241.

${ }^{18}$ Moreno González y Martínez Shaw (2016, pp. 26 y 27) afirman que don García nació en Medina de las Torres, y que a los tres o cuatro años la familia se avecindó en Zafra. En notas 68 y ss., información a partir del Libro de Bautismos n ${ }^{\circ}$, año 1549, f. 103r, de la Parroquia de Nuestra Señora del Camino de Medina de las Torres.

${ }^{19}$ Gil, 2009, 292.

${ }^{20}$ Introducción a la edición inglesa de sus comentarios (2017, p. 46).

${ }^{21}$ Sobre el viajero italiano ver: Pietro della Valle, Viaggi di Pietro della Valle il pellegrino: descritti da lui medesimo in 54 lettere familiari...: divisi en tre parti, cioè La Tvrchia, La Persia, e l'India, le quali hauran per aggiunta, se Dio gli dará vita, la quarta parte, che conterrá le figure di molte cose memorabili. Roma: Vitale Mascardi, 1650, pp. 731-733. También Antonio Invernizzi (ed.), Il Genio vagante. Babilonia, Ctesifonte, Persepoli in racconti di viaggio e testimonianze dei secoli XII-XVIII. Turín: Edizioni dell'Orso 2005. Sobre su encuentro con el embajador español, léase el texto de Córdoba Zoilo (2011-2012): Viaje, hallazgos y fortuna de dos viajeros europeos del siglo XVII en Irán. García de Silva y Pietro della Valle.
} 
murió el 22 de julio de 1624 a 35 grados de Norte, ciento y diez leguas de las islas de Flores y Cuervo, tal y como reza en nota conservada junto al manuscrito de los Comentarios, y que publicó Manuel Serrano y Sanz en su edición de 1903.

\section{La edición de los Comentarios de don García de Silva y Figueroa}

La embajada de don García de Silva al shah de Irán de parte del rey Felipe III es sin duda la más importante de las enviadas desde parte española. Fue una embajada complicada, fiel reflejo del mal gobierno que desde la Monarquía hispánica se hacía de aquellas tierras, de la corrupción de algunos y de los intereses encontrados dentro de la propia Monarquía hispánica y también frente a la iraní. Como también es complicadísima la publicación de sus Comentarios, lo cual tendrá como consecuencia su general desconocimiento durante mucho tiempo (salvo en círculos muy específicos) y su poco reconocimiento en cuanto a la importancia de sus aportaciones entre la comunidad científica internacional.

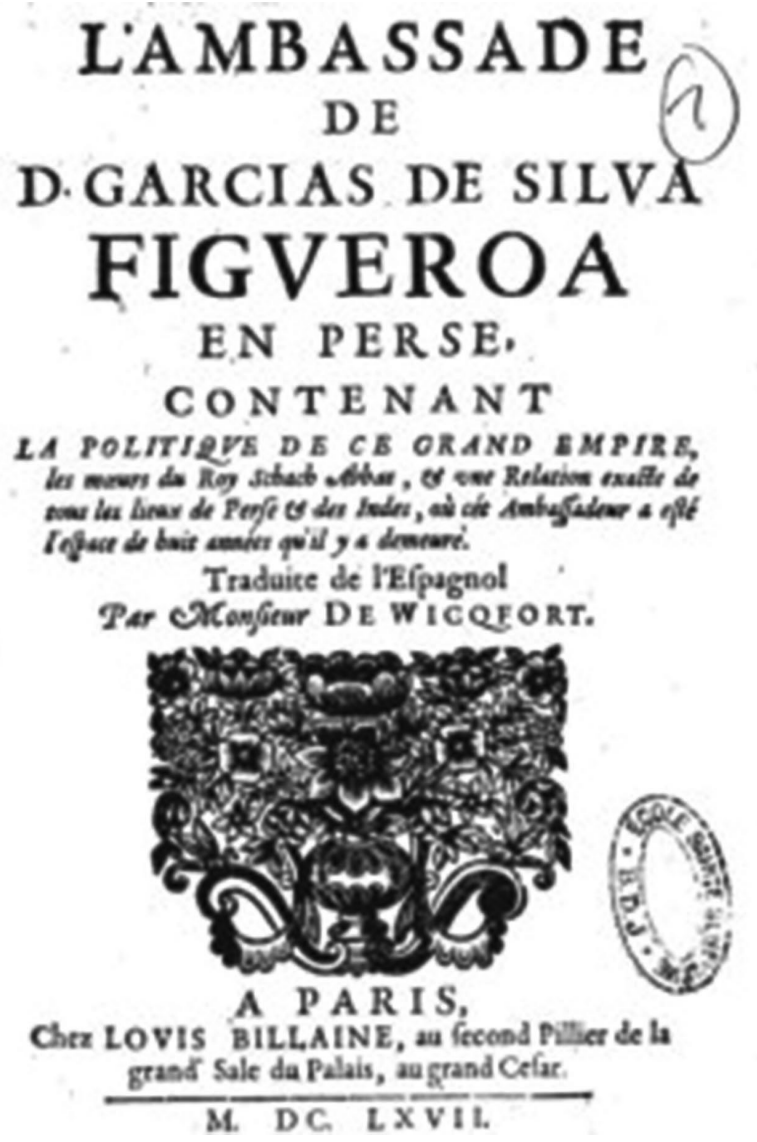

Fig. 5.- Los Comentarios de don García en la edición francesa de Wicqfort de 1667.

Ya hemos dicho que don García murió en su viaje de vuelta, tal y como se señala en la nota que permaneció en el manuscrito, y que se publicaría por primera vez en la edición de la Sociedad de Bibliófilos españoles en 1903 y 1905. No sabemos dónde se conservó este manuscrito, que se empezó a escribir desde el inicio de la misión, de mano del propio embajador, y lo continuó casi hasta el último día de su vida. Casi de forma inmediata se debió hacer una copia, en la que faltaban, sin embargo, los dos primeros libros. Y es ese segundo manuscrito el que traduciría al francés y edita M. Wickfort en 1667. En la Historia del Gran Tamorlán y la narración de la embajada hecha por Ruy González de Clavijo de parte de Enrique III de Castilla al mandatario mongol (entre 1403 y 1406) publicada en 1782, además 
de un breve discurso hecho por Gonzalo Argote de Molina, el editor, Antonio de Sancha, incluye una Vida del Gran Tamorlán sacada de los Comentarios de don García de Silva. Por cierto, la primera edición de la embajada de Ruy González de Clavijo viene realizada por Argote de Molina, en 1582, y está dirigida a Antonio Pérez, Secretario de Estado de Felipe II.

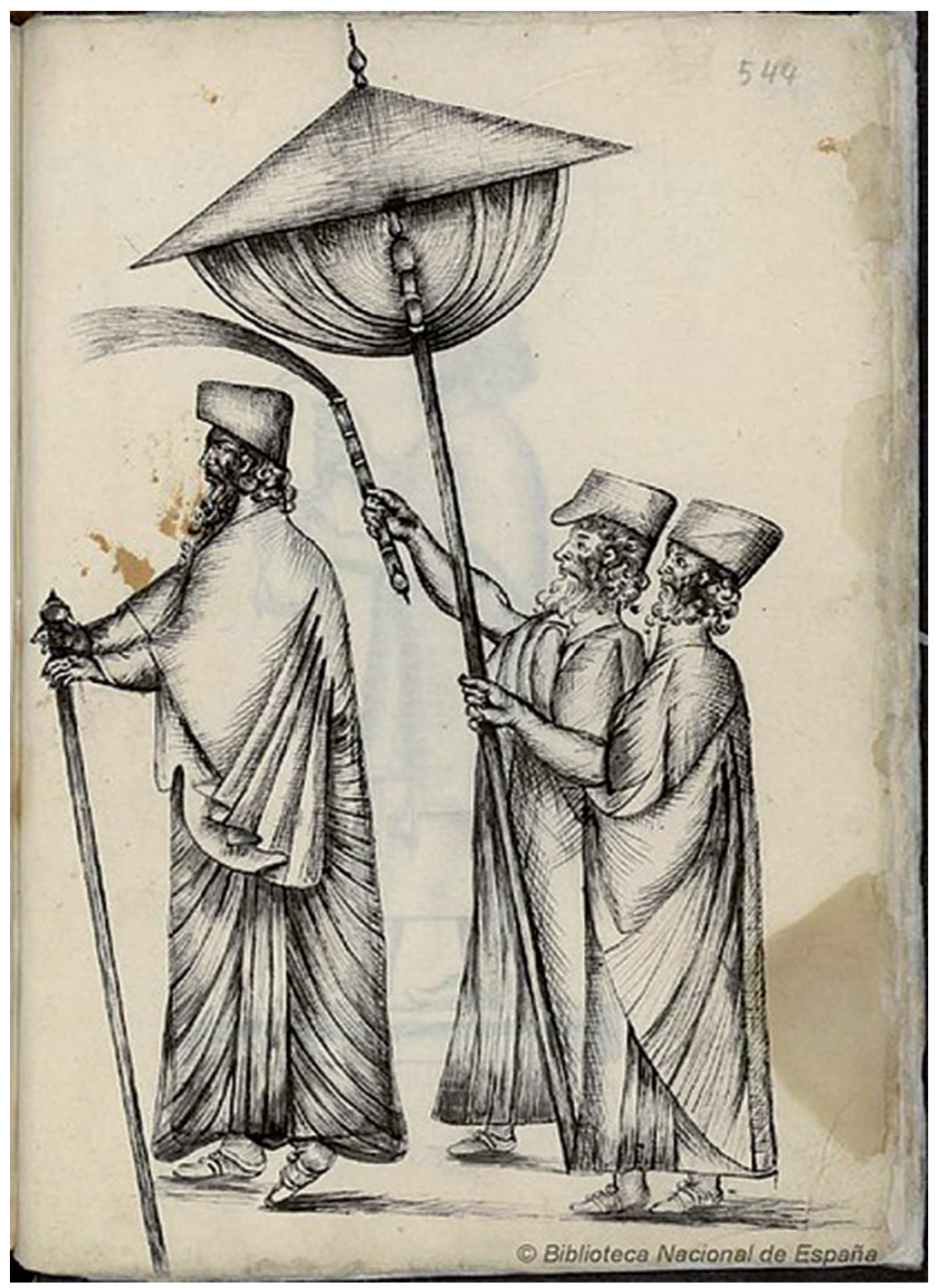

Fig. 6.- Los Comentarios de don García en la edición de 1903. La primera publicada en español y completa.

El manuscrito original y su copia, conocidos por unos pocos bibliófilos, y algún especialista en Oriente, durmieron el sueño de los justos hasta que el orientalista y bibliófilo Pascual de Gayangos ${ }^{22}$ los compró en una librería de viejo y posteriormente los editara la Sociedad de Bibliófilos Españoles, en dos tomos, en 1903 y 1905, bajo la dirección de Manuel Serrano y Sanz. Estos manuscritos, que sirvieron de base a esta edición, están hoy en la Biblioteca Nacional de Madrid. Posteriormente, se han ocupado del embajador a Persia el

\footnotetext{
${ }^{22}$ Pascual de Gayangos y Arce (1809-1893), arabista, numerario de la Real Academia de la Historia, está presente en la formación del Archivo Histórico Nacional y fue quien realizó el catálogo de los manuscritos españoles del British Museum. Además de las obras que escribió, su labor como editor en la Biblioteca de Autores Españoles de Manuel Rivadeneyra y con la Sociedad de Bibliófilos Españoles es absolutamente fundamental. Para ciertos temas, los libros que fueron de su biblioteca, hoy en la Biblioteca Nacional, siguen siendo la parte sustancial de estudio. Es obvio que estuvo involucrado en la primera edición de estos manuscritos en español.
} 
cronista oficial de Zafra Francisco Croche de Acuña, el profesor Joaquín Córdoba ${ }^{23}$, Carlos Alonso $^{24}$, Luís Gil ${ }^{25}$ y en los últimos años ha sido objeto de ulteriores estudios, de una edición de su texto en inglés ${ }^{26}$, y otra en español, realizada desde Portugal $^{27}$, que viene acompañada de estudios sobre el texto y sobre el contexto de la embajada. Manolo Espaliú ${ }^{28}$ ha realizado un recorrido fotográfico siguiendo el trayecto y el texto del embajador.

\section{Los estudios geopolíticos}

En este apartado incluimos textos que pueden ser consecuencia directa de estas embajadas que estudiamos (por ejemplo el texto de don Juan de Persia), o bien que uno de sus protagonistas aprovechase la información y el bagaje de este viajes y otros para plasmar su conocimiento internacional en un tratado político (el Peso político de todo el mundo de Anthony Sherley), o bien el trabajo de un viajero coetáneo, vinculado a la Monarquía Hispánica y que publica su viaje y una historia de Irán basándose en un cronista iraní (Las Relaciones de Pedro Teixeira). Todos ellos se enmarcan en el amplio mundo editorial de estos años que publica estudios políticos de amplio espectro ${ }^{29} \mathrm{o}$ centrados en historias nacionales. No son una excepción, pero sí es una novedad, la cantidad de tratados de distinto ámbito que se dan en muy pocos años, y que tienen al mínimo vinculación con estas relaciones entre Irán y la Monarquía hispánica en torno al reinado de Abbas I.

Entre finales del siglo XVI y principios del XVII hay cuatro Pedro Teixeira portugueses muy vinculados con la corona española ${ }^{30}$ publicando sobre estos temas. Uno de ellos es el famoso cartógrafo autor del mapa de Madrid o del monumental Atlas que también firmó. Pero nuestro protagonista es el autor de las Relaciones de Pedro Teixeira del Origen, Descendencia y successión de los Reyes de Persia, y de Harmuz, y de un viaje hecho por el mismo autor dende la India Oriental hasta Italia por tierra, publicadas en Amberes en 1610.

En realidad, el título lo dice todo y, además del viaje y de la historia de los reyes de Hormuz, presenta una historia de Irán en forma de genealogía de sus reyes, basándose en la obra del cronista contemporáneo Mir Kwand, Mircondo o Mirkhondo, cuya obra conoció en Irán, y en la que se basó para desarrollar su estudio sobre la historia de aquel país. Esta historia toma como base la del historiador iraní, pero a veces para contradecirle, o integrar también visiones e historias europeas sobre aquellas tierras. No hay que entender que fuese

\footnotetext{
${ }^{23}$ En la edición del catálogo de la exposición en el MAN sobre españoles en Oriente (Córdoba Zoilo y Pérez Díe, 2006), en el monográfico de la revista Arbor (2005) o en el homenaje a Donny George de la revista ISIMU (2011-2012). Ver además sus artículos citados en la Bibliografía.

${ }^{24}$ La embajada a Persia de D. García de Silva y Figueroa (1993).

${ }^{25}$ El Imperio luso-español y la Persia safávida (2006 y 2009).

26 Turley 2017.

${ }^{27}$ Dirigida por Rui Manuel Loureiro, en 4 vols, Lisboa: Centro de História de Além-Mar, 2011. Comentarios de Don Garcia de Silva e Figueroa (2 vols.), además de otro de anotaciones y estudios y otro de estudios.

${ }^{28}$ Espaliú 2017. Viaje a Persia: García de Silva y Figueroa.

${ }^{29}$ En este apartado se podría citar la obra de Allain Manesson Mallet: Description de l'Univers, contenant les differentes systemes du monde, les Cartes generales \& particulieres de la Geographie Ancienne \&Moderne: Les Plans \& les Profils des principales Villes\& des autres lieux plus confiderables de la Terre; avec les Portraits des Souverains qui y commandent, leurs Blafons, Titres \& Livrées: Et les Moeurs, Religions, Gouvernemens \& divers habillemens de chaque Nation. París, chez Denys Thierry, 1683.

${ }^{30}$ Además de los dos señalados en el texto, otro Pedro Teixeira publicará un Naufragio de Jorge de Alburquerque e Prosopopeia a seu lauvor, en Lisboa en 1601; y Pedro Teixeira Malato, que acompañó la fundación de Pará, y fue luego su gobernador, escribió: Viaje del Capitán Pedro Teixeira aguas arriba del Río del Amazonas, publicado por primera vez por Marcos Jiménez de la Espada. Sobre nuestro Pedro Teixeira y su viaje, ver Fuente del Pilar 2005.
} 
una mera traducción, y tampoco que respetase siempre la fuente. La utilizó, la plasmó en parte, pero también la modificó y amplió según su conveniencia.

Es una amalgama de textos de todo tipo, a veces discutibles en su inclusión en una obra como esta, pero que conoció un éxito contemporáneo, si atendemos a sus traducciones: en 1633 al latín, fragmentada, en 1681 al francés y en 1715 traducido al inglés, con el título de History of Persia, por John Stevens. La historia de los reyes de Persia, de su descendencia y sucesión, la separa en dos partes, antes y después de la llegada de los árabes a Irán, y termina con Abbás I, de perfecta actualidad en ese momento, también en Europa por todas las embajadas cuyos resultados bibliográficos estamos estudiando.

Uruch Bach, don Juan de Persia, había venido a España en 1601. Escribió sus Relaciones en 1604, donde cuenta con profusión de detalles el viaje de la embajada con la que vino desde Persia. A esta narración del viaje preceden dos libros con noticias históricas y geográficas sobre Persia, donde se habla de las costumbres, del ejército, de la monarquía y también de la historia de Irán, comenzando con Ciro. El libro II narra la historia iraní del siglo XVI, con mucho más detalle que toda la anterior, relativa al gobierno de los safávidas ${ }^{31}$. A partir de un momento en la línea de narración, su relato se basa en el testimonio de su padre: Eultán Alí Bec Bayat, personaje destacado de la nobleza iraní. Después narrará la historia de Abbas I el Grande, que sube al trono en 1588.

Por una parte, a tenor de su procedencia, Uruch Bach/don Juan de Persia podría haber deshecho errores referidos a la historia de su país, o geográficos sobre su tierra, o valorar fábulas habituales en este tipo de libros referidos a su lugar de origen, pero solo lo hace en contadas ocasiones, no quedando clara, además, la participación en la redacción del texto de fray Alonso Remón ${ }^{32}$. El libro utiliza fuentes de la época ${ }^{33}$ como De la Monarquía eclesiástica o Historia universal del mundo, de fray Juan de Pineda ${ }^{34}$, las Relaciones universales del mundo, de Juan Botero Benes ${ }^{35}$ y la Historia de la guerra entre turcos y persianos de Jan Tomas Minadoy ${ }^{36}$. Cuánto hubo de ayuda con el español del nuevo converso, o del acopio de datos de estas publicaciones por parte de fray Alonso, no lo sabemos con certidumbre, pero sí se podría hablar de un libro que recoge en parte lo que en occidente se sabía sobre la historia persa, y que responde también a una fuente que conocía bien la historia contemporánea de ambos lares, que narra casi de primera mano una parte de la historia desde óptica persiana, y que integra por lo tanto fuentes muy distintas para conocer la historia y la realidad contemporánea del país de Irán.

El Peso politico de todo el mundo, firmado por sir Anthony Sherley, es quizá el último de sus proyectos o planificaciones que sobre muchos temas redactó a lo largo de su vida. No sabemos cuándo se redactó exactamente, pero sí que estaba dedicado al Conde Duque de Olivares, lo cual marca una fecha por su inicio de gobierno, en tiempos de Felipe IV. De los

\footnotetext{
${ }^{31}$ Alonso, en la edición de 1946, habla de Sofíes, p. 9.

${ }^{32}$ Relaciones de don Juan de Persia, 1946, p. 11.

${ }^{33}$ Relaciones, 1946, p. 13.

${ }^{34}$ Piñeda, Juan de. Los treinta libros de la Monarchia ecclesiastica, o Historia universal del mundo, divididos en cinco tomos... Compuestos por Juan de Piñeda, fraile menor de la Observancia. Salamanca, casa de Juan Fernández, 1588.

${ }^{35}$ Botero Benés, Iuan. Relaciones universales del mundo de... Traducidas a instancia de don Antonio López de Calatayud, Corregidor de las dezisiete villas, y Regidor de Valladolid, por su Magestad: por el Licenciado Diego de Aguiar su Alcalde mayor. Valladolid, 1603.

${ }^{36}$ Minadoy, Iuan Tomas. Historia de la guerra entre turcos y persianos, escrita por... en quatro libros, començando del año de 1576, que fueron los primeros motivos della hasta el año de 1585... Traducida de Italiano en Castellano por Antonio de Herrera. Impressa en Madrid por Franc. Sanchez, 1588.
} 
cuatro manuscritos del texto conservados en la Biblioteca Nacional ${ }^{37}$, habría un borrador, un manuscrito ya definitivo que perteneció a la biblioteca particular de Felipe IV, y dos manuscritos que contienen el texto completo, encuadernados en dos tomos, bajo el rótulo "Antonio Pérez", de nuevo Antonio Pérez. El secretario de Felipe II aparece vinculado a distintas publicaciones sobre Oriente, no sabemos su grado de implicación política al respecto, y no imaginamos por qué aparece su nombre en una publicación en principio posterior a su muerte (1611).

El Peso político de todo el mundo es un análisis geoestratégico mundial con España como epicentro. Analiza las relaciones políticas como un juego, a distintos niveles, entre potencias, y trata de estudiar más posibilidades en un sistema mundo en función de su potencial económico. Por eso le da tanta importancia a América, todavía con grandes posibilidades ni siquiera exploraddas y en gran parte bajo control español, donde las potencias europeas, que le han quitado la hegemonía, tratan de asentar también su presencia, cuanto más económica, mejor.

En el tomo ${ }^{38}$ trata sobre España, Francia, Alemania, el Papa, Venecia, Florencia, los príncipes menores de Italia, Génova, Saboya, en un capítulo: Tirol, Bohemia, Morabia, Stiria, Slavia, Carinthia, Austria y los Estados patrimoniales del Emperador, sigue con Polonia, Moscovia, Catay, Suecia, Dinamarca, Inglaterra y los Rebeldes. En el tomo II continúa sobre Berberia, Turco; Abasia, Congo y Angola; Cabo de Buena Esperanza, Cafala, Mozambique, Quiloa, Melinde y Mambasa; Persia, El Gran Mogol; El Dialcan, Calicut, Cochin y Malabar; Ceilán; luego Sumatra, Marsinga, Guiago, Bengala, Pegu, Siam, Calimana, Abaa, Borneo, Cochin China y todos los más potentados mayores y menores hasta la China, China y Japón, Filipinas y Malaos, y por último los puertos que los ingleses y rebeldes pueden tomar en el mar del sur demás de los que tienen pasados en trechos de Magallanes por toda la costa del Brasil, y en el archipiélago de la India occidental, hasta la desembocadura de la Baama y la tierra firme de la Florida. Esta enumeración de lugares es buena muestra de los actores que Sherley entendía que había que tener en cuenta desde la política internacional española, una especie de El Estado del Mundo ${ }^{39}$ de cuando el inglés escribió la obra. De algún modo su obra es el resumen final de los proyectos que presentó, de sus análisis del marco internacional en el que situaba sus proyectos de muy distinto tipo, y que fueron tomados solo a veces en cuenta y muy pocas veces, solo al principio de su vinculación con España, fueron puestos en práctica.

Con todas las reservas que la falsa modestia de un personaje como Sherley impone, que es más bien muestra de un orgullo mal contenido, pero quizá merecido, no deja de estar vigente hoy lo que dice en la dedicatoria al Conde Duque ${ }^{40}$ :

"Confieso, Escmo. Señor, que esta empresa es muy soberbia, de gran trabajo, y muy dificultosa y casi imposible para poder llevar a buen puerto con ella: puesto que la experiencia de un hombre, adquirida meramente en los días de una vida (...) es vanidad de presentar a V.E relaciones de los que han dicho y escrito; por ser lo que dicen, y escriben (la mayor parte) relaciones de otros y tales relaciones, más de otros: y que solamente apuntan ciudades, traxez y monstruosidades nunca vistas, que cada Peregrino o mercader refiere (...)"

A todo esto, él contrapone que su obra es personal y basada en su experiencia, la cual fue siempre su gran argumento, y por eso fue temido. Otras cosas son las intenciones, o que quisiera tocar teclas que le devolviesen el favor perdido, cosa que no sabemos juzgar. $Y$ en cuanto a las relaciones que no son más que relaciones de otros y a su vez de otros más... es fantástica su actualidad.

\footnotetext{
${ }^{37}$ Edición de Viñas y Mey, 1961, p. IX.

38 Índice propuesto en la edición de 1946, p. 109. Se mantiene en parte la grafía y la nomenclatura.

${ }^{39} \mathrm{Me}$ refiero al anuario económico geopolítico mundial que cada año publica la editorial Akal.

${ }^{40}$ Ed. de 1961, de Carmelo Viñas y Mey, pp. 1 y 2.
} 


\section{Viajes por el mundo coetáneos}

Los años en los que se desarrollan estas embajadas se inscriben en la Época de los descubrimientos europea, en ese momento sin aquel claro protagonismo de la Monarquía Hispánica y que sin embargo no es ajena a su control ni impulso. También, como sucedió con García de Silva, puede darse que una embajada española sea cortocircuitada en territorio portugués, por sentimientos aparentemente nacionalistas, pero también por miedo al control y examen por parte del poder real acerca del gobierno que se estaba ejerciendo en estos territorios. No sería la primera vez, ni la última, que una buena bandera es utilizada para tapar la corrupción.

No puede ser casual que en 1614 se publicasen en Lisboa y en Madrid, sendos periplos por el mundo que habían sido escritos décadas antes. Las ediciones de la Peregrinaçāo de Mendes Pinto y el Viaje del Mundo de Ordoñez de Ceballos deben ser entendidos en el marco colonial y aventurero, mitad exploración mitad control político del mundo que se estaba descubriendo (esa es la óptica europea) y que estaba bajo el control de las monarquías hispánicas. Amos protagonistas, por cierto, fueron en algún momento de su vida sacerdotes.

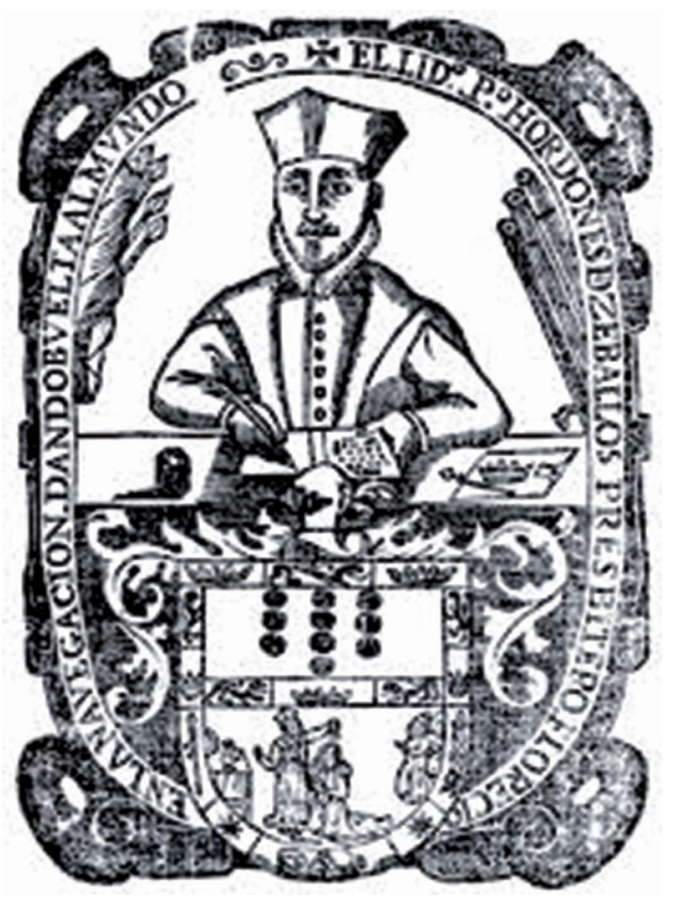

Fig. 7.- Pedro Ordoñez de Ceballos, tal y como aparece en su libro.

Pedro Ordoñez de Cevallos ${ }^{41}$, soldado y corsario antes que sacerdote, natural de Jaén, dedicó treinta y cinco años de su vida a viajar con distintas misiones, con distintos objetivos, que después, trufado de otros hechos más o menos aprendidos o imaginados, plasmó en sus libros. Pudo nacer hacia 154542, y debió morir hacia 1630. Su Viage del Mundo está dividido en tres libros en las que narra sus viajes entre América, Asia y Europa, sus aventuras, lo que supo o aprendió de historias locales y nacionales, y quizá también maravillas más o menos asentadas en el mundo medieval, sin que quede claro cuánto hay de verdad en ellas. Su Viage del Mundo se publicó en Madrid en 1614, el mismo año que su Quarenta Triunfos de la Santísima Cruz de Christo N.S. y Maestro, que preveía fuese el cuarto libro del anterior. Trabajó en una Historia de Jaén que publicó Bartolomé Ximenes Patón en 1628. El personaje

\footnotetext{
${ }^{41}$ Ver la edición de Miraguano - Polifemo 1993 y el estudio de Escribano 2005.

${ }^{42}$ Así apuesta Muradas, autor de la corta introducción a la edición de 1993, p. X.
} 
y su obra gozaron de repercusión, como indica que su Viaje fuese reeditado en 1616 y 1691 , o el sorprendente parecido del libro III con el Itinerario del Padre Martín Ignacio de Loyola incluido en la Historia del Gran reino de la China de fray Juan González de Mendoza (Roma, 1585), o distintas traducciones parciales posteriores.

Fernāo Mendes Pinto escribe su Peregrinaçāo (publicada póstumamente en Lisboa en 1614) entre 1569-70 y 1578-80 en su quinta Pragal-Almada, reflejo de sus continuos viajes a Oriente a través del imperio portugués entre 1537 y $1558^{43}$. En su obra, verdad y ficción aparecen mezcladas, y Mendes Pinto debió ver este peligro, pues justifica y ejemplifica muchas de sus afirmaciones a lo largo del todo el texto ${ }^{44}$. Su escrito es una autobiografía en la que el autor recuerda su viaje y, según narra, permite la entrada de bagajes aprendidos o imaginados que van completando el relato.

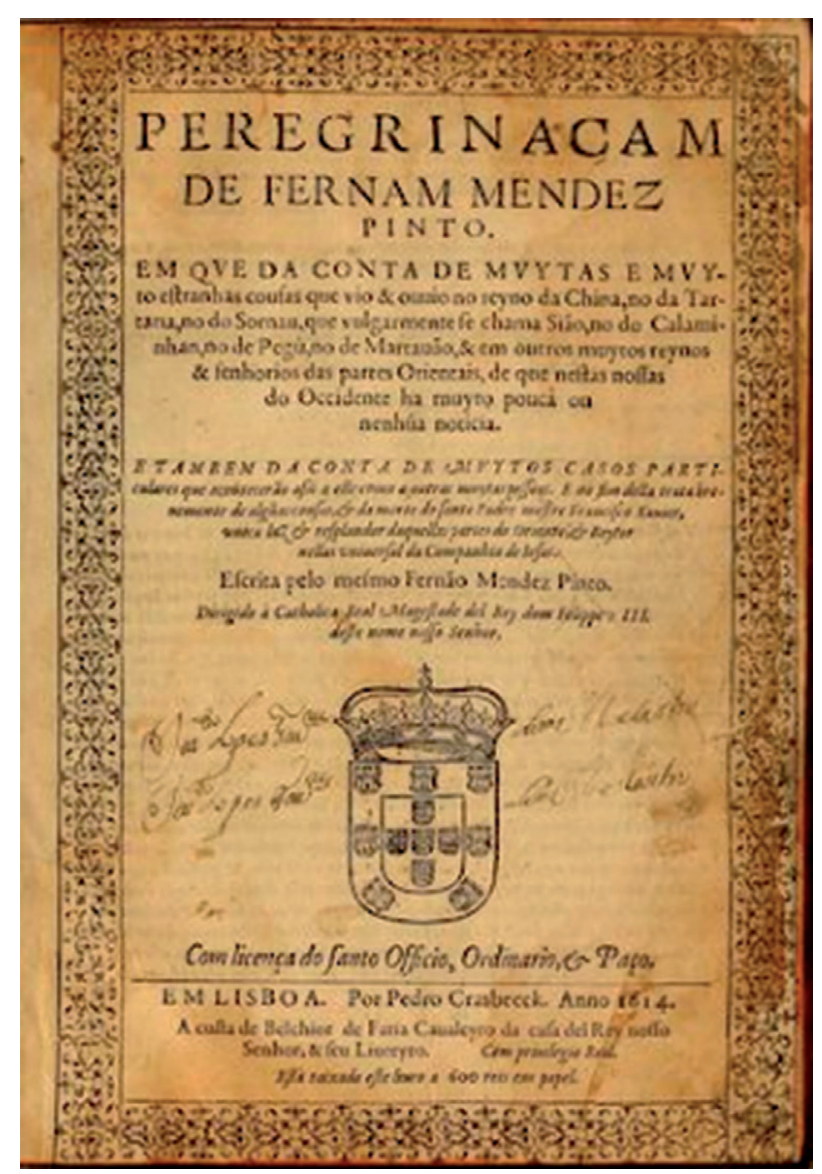

Fig. 8.- La Peregrinación de Fernao Mendes Pinto.

Francisco Herrera Maldonado tradujo al español, para su mayor difusión, el texto de Mendes Pinto en 1620, y de modo paralelo, y muy elocuente en cuanto a su intención, un Catálogo de los autores que han escrito de las Indias Orientales, Japón y China y de sus situaciones, navegación y conquistas (1620) y una Apología en favor de Fernán Mendez Pinto y desta Historia Oriental (Évora, 30 de mayo de 1618). La edición de Herrera corrige datos de la editio prínceps portuguesa, y aporta bibliografía para confrontar los datos aportados

\footnotetext{
${ }^{43}$ Álvarez, 2015, 3. Ver también la explicación a los términos controvertidos en su obra, que se intenta resolver pasado tanto tiempo: Vervloet 2002.

${ }^{44}$ Álvarez, 2015, 4.
} 
por Mendez Pinto ${ }^{45}$. Enrique Gómez, es de suponer que en estos mismos años, en castellano, escribe la segunda parte de la comedia Fernan Mendez Pinto, que dramatiza el periplo de nuestro protagonista. Las dudas y justificaciones sobre la veracidad del texto, o esta comedia en torno suyo, muestran quizá un modo de entender esta narración del viaje, pero son también un fiel reflejo de la visión global que algunos personajes tenían del mundo, y del interés que otros muchos tenían por conocerlo. Ambas visiones tenían como marco la expansión conceptual y geográfica de la Monarquía Hispánica, que sin embargo estaba ya en plena decadencia, como bien se puede observar en otros de los textos estudiados.

\section{Epílogo y Conclusiones}

Al principio de esta comunicación hemos hablado de consecuencias bibliófilas y no de bibliografía, que es lo que hemos estado tratando a lo largo de la misma. Los resultados de aquellos viajes en forma de libros fueron a menudo auténticas joyas, textos únicos por sus aportaciones y por su importancia, aunque no siempre fueron valoradas en su justa medida. Algunos vieron la luz en seguida, y se difundieron en muchas lenguas. Otras eran conocidos solo por los especialistas pero no estaban publicadas, o debieron aguardar mucho tiempo hasta su primea edición. Los Comentarios de Don García de Silva fueron editados por primera vez, de forma completa y en español, en 1903, aunque hubo una edición primera, parcial, en francés en 1667. Los dos manuscritos, el original y una segunda versión, sin los dos primeros libros, en la que se debió basar la edición de Wicfort de 1667, están hoy en la Biblioteca Nacional de Madrid, y provienen de la biblioteca de Gayangos, que los adquirió en librerías de viejo. Es un buen ejemplo de bibliografía que es material de bibliófilos, como son todos los textos citados, y que forman parte de la maravillosa, pero a veces tan difícil en España, aventura del saber nuestra historia.

Independientemente de las aventuras que corrieron cada uno de estos textos, sorprende la cantidad de estas publicaciones, unas describiendo el viaje, otras incluyendo distintos tipos de estudios, y otras auténticos tratados de geopolítica, muy amplios en perspectiva o circunscritos al ámbito iraní, que se dieron en muy pocos años, y que estaban vinculados a la Monarquía Hispánica. En un momento en el que esta monarquía estaba en decadencia, cuando otros poderes europeos pugnaban por el predominio, se abrió una ventana política hacia Irán que no tuvo los resultados pretendidos, no se firmó la alianza contra el Imperio turco, pero sí permitió, vía todos los libros que hemos ido estudiando, publicados en esos pocos años, o reeditando textos antiguos, un conocimiento de la tierra de Irán como nunca antes se había tenido desde Europa, y todo esto se dio desde España y Portugal.

\section{BIBLIOGRAFÍA}

ALONSO, C.

1993 La embajada a Persia de D. García de Silva y Figueroa. Departamento de Publicaciones, Excma. Diputación Provincial de Badajoz.

\section{ÁLVAREZ SELLERS, M.R.}

2015 "Caminos portugueses hacia Oriente: de la "Peregrinação" de Fernão Mendes Pinto a la comedia "Fernán Méndez Pinto" de Enríquez Gómez". Alicante: Biblioteca Virtual Miguel de Cervantes. (Edición digital a partir de Actas del VIII Congreso Internacional de Caminería Hispánica, Madrid, Ministerio de Fomento, CEDEX-CEHOPU, 2008, pp. 1-14.)

\footnotetext{
$\overline{{ }^{45} \text { Álvarez, 2015, } 4 .}$.
} 
CÓRDOBA ZOILO, J. Ma .

1998 "Algunas notas sobre don García de Silva y el descubrimiento del Oriente a comienzos del siglo XVII", in J. Mangas \& J. Alvar (coord.) Homenaje a José María Blázquez, Vol. 1, págs. 353-362.

2001 «La percepción del Irán antiguo y contemporáneo en la obra de los viajeros españoles de los siglos XVII y XIX», in J. M. Córdoba, R. Jiménez Zamudio, C. Sevilla Cueva (eds.), El Redescubrimiento de Oriente Próximo y Egipto. Viajes, hallazgos e investigaciones. Universidad Autónoma de Madrid, Madrid, pp. 1-16.

2005 “Un caballero español en Isfahán. La embajada de Don García de Silva y Figueroa al sha Abbás el Grande (1614-1624)", Arbor 711-712, págs. 645-669.

2006 "La época de los viajeros y el redescubrimiento: colores de Occidente y perfumes de Oriente: los viajeros hispanos de los Siglos de Oro: Don García de Silva y Figueroa, y el redescubrimiento de Irán”, in CÓRDOBA ZOILO J.M. y PÉREZ DÍE, M.C (coord.), La aventura española en Oriente (1166-2006), Viajeros, museos y estudiosos en la historia del redescubrimiento del Oriente Próximo Antiguo, pp. 89-98.

2011-2012 "Viaje, hallazgos y fortuna de dos viajeros europeos del siglo XVII en Irán. García de Silva y Pietro della Valle". Isimu: Revista sobre Oriente Próximo y Egipto en la antigüedad, Nº 14-15, (In Memoriam Donny George), págs. 165-218.

CÓRDOBA ZOILO J.Mª y PÉREZ DÍE, M.C. (coord.)

2006 La aventura española en Oriente (1166-2006). Viajeros, museos y estudiosos en la historia del redescubrimiento del Oriente Próximo Antiguo.

ESCRIBANO MARTÍN, F.

2005 "El viaje del mundo de Pedro Ordoñez de Ceballos", Arbor 711-712, marzo-abril, pp. 581-594.

ESPALIÚ, M.

2017 Viaje a Persia: García de Silva y Figueroa. Un diálogo fotográfico de Manolo Espaliú con los textos de Silva. Teherán.

FUENTE DEL PILAR, J.J.

2005 "Pedro Teixeira y su viaje por Mesopotamia", Arbor 711-712, marzo-abril, pp. 627-643.

\section{GIL FERNÁNDEZ, L.}

2006 y 2009 El Imperio luso-español y la Persia safávida. Tomo I (2006) (1582-1605) y tomo II (2009) (1606-1622). Fundación Universitaria Española, Madrid.

LOUREIRO, R. M. \& RESENDO, V.

2011 Estudios sobre Don García de Silva y Figueroa e os "Comentarios" da embaixada à Persia (1614-1624). Lisboa.

MORENO GONZÁLEZ, J. M. y MARTÍNEZ SHAW, C.

2016 Un extremeño en la Persia del siglo XVII. Nuevos testimonios de la embajada de Don García de Silva y Figueroa (1614-1624). Diputación Provincial de Badajoz, Colección Historia. 


\section{ORDOÑEZ DE CEBALLOS, P.}

1993 Viaje del Mundo. Biblioteca de Viajeros Hispánicos, 8. Miraguano Ediciones \& Ediciones Polifemo. Madrid.

\section{PERSIA, J. de (URUCH Beg)}

1604 Relaciones de don Juan de Persia. Dirigidas a la majestad católica de don Felipe III, rey de las Españas y señor nuestro. Divididas en tres libros, donde se tratan las cosas notables de Persia, la genealogía de sus reyes, guerras de persianos, turcos y tártaros, y las que vio en el viaje que hizo a España: y su conversión y la de otros dos caballeros persianos. Valladolid, por Iuan de Bostillo.

1946 Relaciones de don Juan de Persia. Prólogo y notas de Narciso Alonso Cortes. Madrid, Gráficas Ultra.

\section{SHERLEY, A.}

1961 Peso político de todo el mundo del Conde D. Antonio Xerley. Edición de Carmelo Viñas y Mey. Departamento de Historia Social. Instituto "Balmes" de Sociología. CSIC, Madrid.

2010 Peso de todo el mundo (1622) y Discurso sobre el aumento de esta monarquía (1625). Ed y estudios de Ángel Alloza Aparicio, Miguel Ángel de Bunes y José Antonio Rodríguez Torres. Madrid, Ediciones Polifemo.

SILVA y FIGUEROA, G. de.

1618 (cronología de la BN) Comentarios de don García de Silva que contienen su viaje a la India y de ella a Persia, cosas notables que vió en él y los sucesos de la embajada al Sophi [Manuscrito].

1989 Epistolario diplomático. Edición y estudios preliminares de Luis Gil. Institución Cultural "El Broncense", Cáceres.

2017 The Commentaries of D. Garcia de Silva y Figueroa on his Embassy to Shah Abbās I of Persia on Behalf of Philip III, King of Spain. Brill, Leiden/Boston.

\section{TEIXEIRA, P.}

1994 Relaciones de Pedro Teixeira del origen, descendencia y succession de los reyes de Persia, y de Harmuz, y de un viaje hecho por el mismo autor dende la India Oriental hasta Italia por Tierra. Biblioteca de Viajeros Hispánicos 12. Miraguano Ediciones \& Ediciones Polifemo. Madrid. (Edición original publicada en Amberes en 1610).

TURLEY, T.S. \& SOUZA, G. B.

2017 The Commentaries of D. García de Silva y Figueroa on his Embassy to Shah Abbās I of Persia on Behalf of Philip III, King of Spain. Brill, Leiden/Boston.

VERVLOET, C.

2002 Fernán Méndez Pinto travels: explanation of difficult words. Barcelona. 